\title{
Clinicohematological Profile of Anemia in Children - A Retrospective Descriptive Study
}

Dr. Pramila Ramawat ${ }^{1 *}$, Dr. Nilesh Jain ${ }^{2}$

${ }^{1}$ Assistant Professor, ${ }^{2}$ Associate Professor, Pediatric Department, MGM Medical College Indore, India

DOI: $10.36347 /$ sjams.2020.v08i10.012

| Received: 16.08.2020 | Accepted: 24.08.2020 | Published: 15.10.2020

*Corresponding author: Dr. Nilesh Jain

Abstract

Original Research Article

Aim: To study clinical spectrum and hematological profile of anemia and its association to age, gender and nutritional status in children aged 1 month to 14 years admitted in tertiary care hospital of Central India. Material and Methods: A retrospective descriptive study conducted by collecting data from hospital record system about children aged 1 month to 14 years admitted between Augusts to December 2019. Data analyzed for demography, clinical profile including anemia type, severity, etiology and effects, hospital stay and outcome. Result: In our study boys were outnumbered girls in hospitalization. Most common cause was nutritional anemia based on etiology. Infection and malnutrition were found in significant numbers of patients. Bicytopenia and pancytopenia were also noticed in patients. Conclusion: Nutritional anemia is most common cause of anemia in childhood especially in developing countries which can be prevented by proper nutritional support in growing age. Parents and caregiver need awareness regarding effect and causes of anemia and how to prevent it.

Keywords: Nutrition, Hemoglobinopathy, Transfusion.

Copyright $\left({ }^{\circ} 2020\right.$ The Author(s): This is an open-access article distributed under the terms of the Creative Commons Attribution 4.0 International License (CC BY-NC 4.0) which permits unrestricted use, distribution, and reproduction in any medium for non-commercial use provided the original author and source are credited.

\section{INTRODUCTION}

Anemia is a very prevalent condition all over world and significant cause for high morbidity. As estimated by WHO 1.62 billion children affected worldwide among them most affected age group is preschool children $(47.4 \%), 25.4 \%$ school age children are also suffering from anemia [1]. Reasons for high prevalence of anemia in infants and toddlers are many, first and most important reason is lack of knowledge about balanced nutrition in caregivers including timely initiation of complementary feeding, type, amount and frequency of feeding, second reason - recurrent infections affecting feeding and third reason is food fussiness of toddlers. NFHS 4 reports are showing $10 \%$ decrease in anemia prevalence in under 5 children in India, current prevalence of anemia in under 5 children is $58.4 \%$ according to NFHS4 survey. In India prevalence rate varies between different states but above $50 \%$ of children affected in all states $[2,3]$.

Anemia significantly affects child's growth, development, wellbeing and scholastic performance. It decreases appetite of children which affect nutrition and a vicious cycle starts which further worsen situation. It is very important co morbidity in hospitalized children which can prolong hospital stay, increased risk of complications and need of blood transfusion.
Nutritional anemia is most common but preventable cause for anemia in children in developing countries. Emphasis on simple measures like adequate nutrition including breast feeding, timely starting of complementary feeding in infancy, dietary improvement in toddlers and older children, treating helminthic infections and maintain hygiene to prevent recurrent infections which hamper nutrition can decrease the disease burden in society. Hemoglobinopathies are also very important cause for anemia associated with prolong morbidity and high demand for blood transfusion, it also affect psychological wellbeing of child and family. Prevention is the best treatment for hemoglobinopathies. Awareness is required about its impact and prevention in public.

\section{Material And Methods}

A retrospective study was planned in a tertiary care center of central India to assess clinical presentation and hematological profile of anemia in admitted children. It is a hospital based single center analytic study. We included children between 1 month to 14 year of age who were admitted in PICU and pediatric ward of our hospital between Augusts to December 2019 with anemia on day 1 of admission. 
Data was collected by hospital's record section regarding patient's demographic detail, diagnosis, anthropometry, clinical presentation as per prepared questionnaires and investigations for diagnosis of anemia, its severity and underlying cause Hemoglobin, TLC, DLC, platelet, MCV, MCH, MCHC, $\mathrm{PCV}, \mathrm{RDW}$, reticulocyte count and peripheral smear in detail. All these blood indices evaluated by automated analyzer. Reticulocyte count was calculated by staining with brilliant crystal stain method. Patients who were investigated for other laboratory tests relevant to their condition like Hemoglobin electrophoresis, Iron indices, S. B12 level, Bone Marrow examination, G6PD level etc. also recorded in data sheet. Anemia cut off points were defined by hemoglobin level according to age and severity as per WHO guidelines. Malnutrition was also defined according to WHO criteria for SAM.

\section{Inclusion Criteria}

- Children between 1 month to 14 year of age

- Children with hemoglobin level as per WHO guideline for anemia

\section{Exclusion Criteria}

- Children with $\mathrm{k} / \mathrm{c}$ of hemolytic anemia or aplastic anemia

\section{- $\quad$ Age $<1$ month and above 14 years}

Statistical analysis was done by using SPSS version. Descriptive statistics in terms of frequency and percentage was used for categorical variables and mean and SD for continuous variables. Logistic regression, chi square test were used to assess the association of various socio-demographic variables and risk factors to anemia in study participants. A P value of $<0.05$ with 95\% confidence interval was taken as a level of significance.

\section{RESULT}

During study period total 620 patients admitted in PICU and pediatric ward, among these patients 189 patients had were included in the study. Prevalence of anemia was found to be $47.5 \%$ in hospitalized children in the study. In our study $51.3 \%$ children were boys while $48.6 \%$ were girls. Most common age group affected was under 5 children $79.36 \%$ (n- 150). Among these 189 anemic children $8.4 \%$ children were below 6 month, $30.2 \%$ children between 6 month to 1 year of age, $40.7 \%$ children between 1 to 5 year of age, $13.2 \%$ children $5-10$ year of age and $8 \%$ children $10-14$ years of age.

Table-1: Anemia distribution according to gender

\begin{tabular}{|l|l|l|l|l|l|l|l|}
\hline S. No. & Gender & Mild & Moderate & Severe & Total patient & Chi square test & P value \\
\hline 1. & Male & 23 & 43 & 31 & 97 & 4.56 & 0.102 \\
\hline 2. & Female & 26 & 50 & 17 & 92 & & \\
\hline 3. & Total & 48 & 93 & 48 & 189 & & \\
\hline
\end{tabular}

As per hemoglobin level according to WHO guideline for anemia children divided into 3 groups mild (n-48), moderate (n-93) and severe (n-48). Based on MCV values as per normogram (according to age), patients divided in 3 types microcytic (n- 117), macrocytic (n-17) and normocytic (n- 55) anemia.

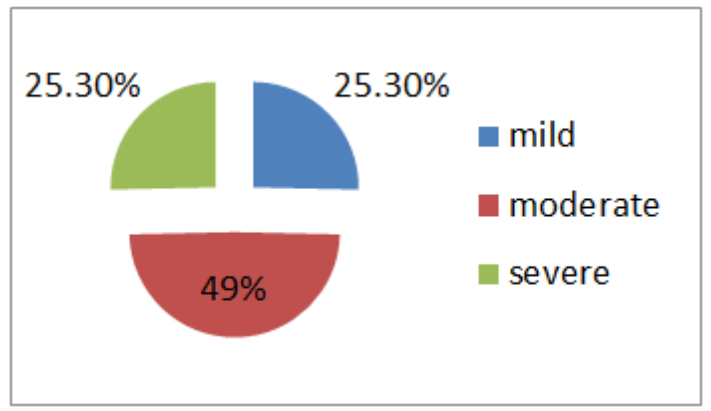

Fig-1: Type of anemia based on $\mathrm{Hb}$ level

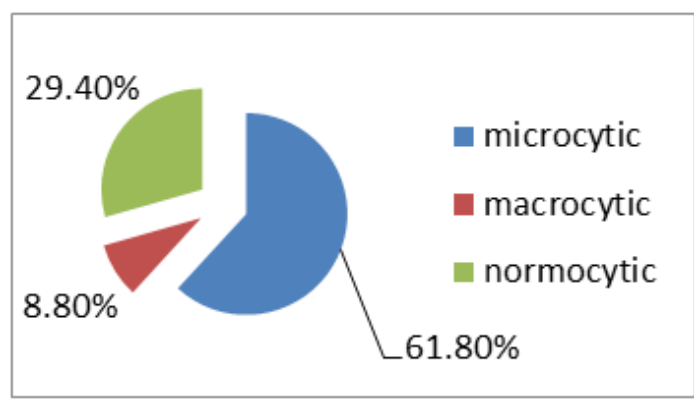

Fig-2: Type of anemia based on MCV values 
Causes of anemia varies, most common cause was nutritional - isolated iron deficiency was present in 40 children, 11 children with B12 deficiency and 6 were suffering from Pre ITS and ITS, 40 children were diagnosed with SAM and 29 children with moderate malnutrition. 24 children presented with hemolytic anemia among these 24 children 6 patient diagnosed with thalesemia, 9 patients with sickle cell anemia, 2 patients with G 6PD deficiency, 3 patients with malaria, 2 with autoimmune hemolytic anemia and 2 patients presented with evidences of hemolysis but no clear etiology was found. 3 patients admitted with pancytopenia and diagnosed as aplastic anemia and in 2 patients leukemia was diagnosed. 1 patient with hemophilia was become anemic due to ongoing bleeding. In 4 patient sepses was reason for anemia. In 16 patient anemias was associated with chronic disease - 1 patient with chronic kidney disease stage 5,8 patients with CHD, 6 patients with cerebral palsy, 4 patients with global development delay, 3 patients with failure to thrive, 2 patients with HIV.

Table-2: Distribution of anemia in children according to age

\begin{tabular}{|l|l|l|l|l|l|l|l|}
\hline S.No. & Age groups & Mild & Moderate & Severe & Total patient & Chi Squere test & P value \\
\hline 1. & $<1$ year & 23 & 32 & 18 & 73 & 6.64 & 0.156 \\
\hline 2. & $1-5$ year & 16 & 45 & 16 & 77 & & \\
\hline 3. & $>5$ year & 9 & 16 & 14 & 39 & & \\
\hline 4. & Total & 48 & 93 & 48 & 189 & & \\
\hline
\end{tabular}

Total 150 children were under 5 year of age, among these children 40 were suffering from severe malnutrition and 29 were with moderate malnutrition and 81 children were well nourished.

Table-3: Distribution of anemia based on nutritional status in under 5 children

\begin{tabular}{|l|l|l|l|l|l|l|l|}
\hline S. No. & Nutrition status & Mild & Moderate & Severe & Total & Chi squere test & P value \\
\hline 1. & SAM & 5 & 25 & 10 & 40 & 13.66 & 0.032 \\
\hline 2. & MAM & 5 & 13 & 11 & 29 & & \\
\hline 3. & Well nourished & 29 & 38 & 14 & 81 & & \\
\hline 4. & Total & 39 & 76 & 35 & 150 & & \\
\hline
\end{tabular}

Infection (20\%) was most common cause for admission. 14 patient admitted with pneumonia, 2 patients with UTI, 18 with sepsis, 2 with TBM, 3 with pulmonary TB. 2 patients was presented with CHF due to anemia, 7 patients had history of pallor and in 10 patient pallor was found on examination and hospitalized for evaluation and management.

\section{Bicytopenia}

Anemia with leucopenia presented in 8 patients. All leucopenic patients had leukocyte count 3000 to 4000 . Infection was cause for leucopenia in all patients and improved. Thrombocytopenia presented with anemia in 28 patients. Some patients presented with severe thrombocytopenia and others with mild to moderate severity. Causes for thrombocytopenia with anemia were SAM in 6 patients, 6 with sepsis, AES in 4, B12 deficiency and ITS in 2 patients, hemolytic anemia 1, CKD 1, Thalesemia 1, DIC 2, Snake bite in 1 patient. All patients improved.

\section{Pancytopenia}

$10 \%$ patients of anemia presented with pancytopenia. Causes of pancytopenia were aplastic anemia in 3 patient proved by bone marrow examination, 4 patients with sepsis, 2 patient with thalesemia major, 1 patient with sickle cell anemia diagnosed by hemoglobin electrophoresis, 1 with cerebral malaria, Pre ITS with B12 deficiency, 3 patient with SAM, unknown in 2 patient. Clinical presentation was fever in $58 \%$ patients majority were LRTI, 4 patients with severe sepsis, 3 with bleeding manifestations ( 1 - hemetemisis, 1- melena, 1petechial rash), 3 patients with pallor and 2 with decrease oral acceptance.

Table-4: Severity of anemia, neutropenia and thrombocytopenia in pancytopenic patient

\begin{tabular}{|l|l|l|l|l|}
\hline S. No. & Severity & Anemia & Neutropenia & Thrombocytopenia \\
\hline 1. & Mild & 0 & 6 & 3 \\
\hline 2. & Moderate & 9 & 3 & 4 \\
\hline 3. & Severe & 10 & 10 & 12 \\
\hline
\end{tabular}

Among these 19 patients 12 patients improved and 7 patient patients expired.

\section{DISCUSSION}

According to WHO reports anemia is a serious global health problem specially affecting children and pregnant females with estimated prevalence rate $42 \%$ in under 5 children. It is more prevalent in developing countries with high prevalence rate $-51 \%$ in children between $0-4$ years and $46 \%$ between $5-12$ years of age [1]. Prevalence of anemia in our study was $43 \%$ in 
children. NFHS survey 4 reported that prevalence of anemia in Indian fewer than 5 children is $58.4 \%$ [2]. In study by prevalence rate was $20.7 \%$ in school children aged between $6-15$ years of age and $18 \%$ by Djokic et $a l$. in school children aged between 4-15 years of age while prevalence rate $52.88 \%$ reported by Sudhagandhi et al. and $37.6 \%$ by Assefa et al. In our study male predominance was found, similar results were found in some studies but female predominance reported by other studies and in one study no difference was found in anemia prevalence between genders.

Nutritional anemia was reported as commonest cause of anemia in children in this study. These results supported by many other studies especially from developing countries [8, 9, 14]. WHO estimated that iron deficiency anemia is responsible for $50 \%$ of cases of anemia in fewer than 5 children [1]. Other micronutrients (eg.- vitamin A, B12, folate and zinc) deficiency are also common culprit for nutritional anemia and it is advised by WHO that diet should be supplemented with these essential micronutrients. In both age group [ 6 month to 23 months and 2 to 12 years] food fortification with micronutrient rich powder advocated by WHO[16,17]. WFI [weekly iron and folic acid supplementation] program for fewer than 5 children and school aged children is a promising initiative by Government of India involving anganwadies and schools [2, 3].

In our study pallor was not a very common finding in mild anemia but found as an important sign in severe anemia. Other studies had similar results. Fever was also a common presentation in our study as well as other studies. Lower respiratory infection is most common cause for admission in our study while another study by found acute gastroenteritis as a common reason for admission. Admission only because of anemia was in 25 children. History of deworming was given by many patients but worm infestation was reported in 12 patient which confirmed by stool examination in 2 patients.

In our study malnutrition significantly associated with anemia and its severity. Childhood under nutrition alone is responsible for approximately $45 \%$ cases of fewer than 5 mortality according to WHO estimation [4]. Malnutrition was significantly associated with anemia and responsible for multiple micronutrient deficiency including iron, zinc, vitamin A, B12 and folate. It is suggested that more than one micronutrient deficiency was responsible for anemia in malnourished children and proper supplementation is must to improve outcome in these patients $[16,17]$.

Infection was most common reason for admission in this study. Similar results were reported in other studies. It can cause sudden fall of hemoglobin due to hemolysis or decrease RBC production in bone marrow but many times underlying micronutrient deficiency is responsible for decrease immunity and exposed children to severe infection requiring hospitalization. Anemia is a risk factor for increased morbidity and prolongs duration of hospital stay in patient with infections.

Pancytopenia is a very serious threat in hospitalized children. We found it in $10 \%$ and bicytopenia in $20 \%$ hospitalized children. Severe pancytopenia was present in 5 children and associated with poor out come. Causes for pancytopenia were aplastic anemia, B12 deficiency, sepsis and hemolytic anemia. Some other studies from South Asia reported aplastic anemia, infection and hematological malignancies are common cause for pancytopenia [18].

\section{CONCLUSION}

In our opinion nutritional anemia is a prevalent cause of anemia especially in fewer than 5 children and significantly associated with faulty dietary practices. It can be prevented by improving awareness in people about serious manifestations of anemia in children including effect on growth and development with emphasis on its association with malnutrition so micronutrient supplementation in diet adequately provided to children. Second preventable cause is hemolytic anemia (thalesemia and sickle cell anemia) requires social awareness for premarital and prenatal counseling and screening in first trimester of pregnancy for timely decision.

\section{REFERENCES}

1. The global prevalence of anaemia in 2011. Geneva: World Health Organization; 2015 (http://apps.who.int/iris/bitstream/10665/177094/1/ 9789241564960_eng.pdf?ua=1\&ua=1, accessed 1 December 2016).

2. Indian Institute for Population Sciences (IIPS) and MoHFW. National Family Health Survey - 4. 2017. Available from: http://rchiips.org/nfhs/pdf/NFHS4/ India.pdf. Accessed June 12, 2017.

3. Dhirar N, Dudeja S, Khandekar J, Bachani D. Childhood Morbidity and Mortality in IndiaAnalysis of National Family Health Survey 4 (NFHS-4) Findings. Indian pediatrics. $2018 \mathrm{Apr}$ 1;55(4):335-8.

4. WHO. Hemoglobin concentrations for the diagnosis of anemia and assessment of severity. Vitamin and Mineral Nutrition Information System. Geneva: World Health Organization; 2011.

5. Kanchana, Madhusudan SR, Ahuja S, Nagaraj N. Prevalence and risk factors of anemia in under fiveyear-old children in children's hospital. Int J Contemp Pediatr. 2018; 5:499-502.

6. Mahroof MK, Khan SA, Saldanha P. Clinical study of anemia in rural school children of Mangalore, Karnataka, India. Int J Contemp Pediatr. 2019; 6: 416-21. 
7. Sudhagandhi B, Sundaresan S, William WE, Prema A. Prevalence of anemia in the school children of Kattankulathur, Tamil Nadu, India. International Journal of Nutrition, Pharmacology, Neurol Dis. 2011;1(2):184

8. Assefa S, Mossie A, Hamza L. Prevalence and severity of anemia among school children in Jimma Town, Southwest Ethiopia. BMC Hematol. 2014; 14(1):1-9.

9. Stevens GA, Finucane MM, De-Regil LM, Paciorek CJ, Flaxman SR, Branca F, Peña-Rosas JP, Bhutta ZA, Ezzati M, Nutrition Impact Model Study Group. Global, regional, and national trends in haemoglobin concentration and prevalence of total and severe anaemia in children and pregnant and non-pregnant women for 1995-2011: a systematic analysis of population-representative data. The Lancet Global Health. 2013 Jul 1;1(1):e16-25.

10. Cardosa MA, Scopel KK, Muniz PT, Villomore E Ferrira UM. Underlying factors associated with anemia in Amazonian Children a population based, cross sectional study. PLOS one2012;7:e36341.10.137/journel.pone.0036341 [PMC free article] [Pub Med] [Cross Ref] [Google Scholar]

11. Santo LL, Fawzi WW, Cardoso MA. PLOS one 2012; 7:e36341.10.137/journel.pone.0036341 [PMC free article] [Pub Med] [Cross Ref] [Google Scholar]

12. Ramana Shastry CPV. Study on clinical and hematological profile of Anemia in children aged 5 t0 12 years in rural Telangana. J PediatrRes. 2017; 4(07):488 493.doi:10.17511/ijpr.2017.07.09.
13. Madoori S, Ramya C, Valugula S, Sandeep G, Kotla S. Clinico hematological profile and outcome of anemia in children at tertiary care hospital, Karimnagar, Telangana, India. Int J Res Med Sci. 2015; 3:3567-71

14. Janjale A, Pande S, Sonawane R, Ahire N, Sonawane S. A Study of Severe Anemia in Children in a Tertiary Care Institute. MVP Journal of Medical Sciences. 2018; 5(1):33-38.

15. Shazia M, Salma S, Akbar N. Etioloigcal spectrum of pancytopenia based in bone Marrow examination in children. J Coll Physicians Surg Pak. 2008;18(3):163-167.

16. WHO guideline: Use of multiple micronutrient powders for point-of-use fortification of foods consumed by infants and young children aged 6-23 months and children aged 2-12 years. Geneva: World Health Organization; 2016. Licence: CC BY-NC-SA 3.0 IGO. Guideline:

17. Use of multiple micronutrient powders for home fortification of foods consumed by infants and children 6-23 months of age. Geneva: World Health Organization; 2011 (http://apps.who.int/iris/bitstre am/10665/44651/1/9789241502047_eng.pdf, accessed 1 December 2016).

18. Jan AZ, Zahid B, Ahmad S, Gul Z. Pancytopenia in children: A 6-year spectrum of patients admitted to Pediatric Department of Rehman Medical Institute, Peshawar. Pakistan Journal of Medical Sciences. 2013 Sep;29(5):1153.

19. Sahu T, Sahani NC, Patnaik L. Childhood anemia: a study in tribal area of Mohana blocks in Orrisa. Indian J Com Med. 2007;32(1):106-8. 